\title{
Is conversion from laparoscopic to open surgery in colorectal cancer predictable in the preoperative period?
}

\author{
D Sadettin Er, (1) Sabri Özden, (1) Ibrahim Ağaçkıran, (1) Hüseyin Berkem, \\ (1) Aziz Ahmet Surel, (1) Mesut Tez, (1) Bülent Cavit Yüksel \\ Department of General Surgery, Ankara City Hospital, Ankara,Turkey
}

\begin{abstract}
Introduction: This study aimed to evaluate the risk factors associated with conversion from laparoscopic colorectal resection to open surgery and investigate whether the possibility of such a conversion requirement can be predicted in the preoperative period.

Materials and Methods: Between 2014 and 2018, following the diagnosis of colorectal cancer, 467 patients underwent laparoscopic resection in our general surgery clinic, of whom 126 were included in this study based on the availability of the parameters of conversion of laparoscopic rectal resection to open surgery (CLRROS) and the Cleveland Clinic Foundation colorectal laparoscopic conversion (CCF-CLC) scores.

Results: Of the 126 patients included in this study, 97 (76\%) underwent laparoscopic resection (classified as Group 1), and 29 (24\%) cases were converted to open surgery (classified as Group 2). The mean agetstandard deviation (SD) was $58 \pm 13$ and $62 \pm 15$ years for Groups 1 and 2, respectively. The CLRROS and CCF-CLC scores were $8 \pm 8$ and $16.6 \pm 9.2$, respectively in Group 1 , and $17 \pm 10$ and $17.7 \pm 10.5$, respectively in Group 2 . The receiver operating characteristic analysis results were $0.769(95 \% \mathrm{Cl}: 0.666-0.871, \mathrm{p}=0.000)$ and 0.508 ( $95 \% \mathrm{Cl}: 0.382-0.634, \mathrm{p}=0.896)$ for the CLRROS and CCF-CLC scores, respectively.

Conclusion: To predict conversion from laparoscopy to open surgery, it was concluded that the CLRROS and CCF-CLC scores could help in selecting cases suitable for laparoscopy and inform patients about the expected postoperative outcomes, as well as minimizing postoperative disadvantages.
\end{abstract}

Keywords: Colorectal cancer; conversion score; laparoscopic surgery.

\section{Introduction}

There has been significant improvement in laparoscopic colorectal surgery since its first application; however, some patients still require conversion from laparoscopic colorectal resection to open surgery due to the size of colorectal lesions, patients' general condition, and the experience of surgeons.
Studies have revealed that a wide body surface area and body mass index (BMI), smoking, a high score in the American Society of Anesthesiologists (ASA) classification, chronic obstructive pulmonary disease, acid and chemotherapy, as well as tumor-specific factors in cancer patients are important risk factors for conversion to an open procedure. ${ }^{[1,2]}$ Furthermore, conversion may rarely 
be necessary when a tumor is not found following bowel resection.

It has also been shown that conversion from laparoscopy to an open procedure has worse outcomes in terms of ileus, septic complications, and oncologic margins compared to cases that do not require such conversion. ${ }^{[3]}$ This study aimed to evaluate the risk factors associated with conversion from laparoscopic colorectal resection to open surgery and investigate whether the possibility of such conversion requirement can be predicted preoperatively.

\section{Materials and Methods}

\section{Patient Data}

Between 2014 and 2018, following the diagnosis of colorectal cancer, 467 patients underwent laparoscopic resection in the general surgery clinics of Ankara Numune Training and Research Hospital. Of these patients, 126 were included in the study based on the availability of the parameters of conversion of laparoscopic rectal resection to open surgery (CLRROS) and Cleveland Clinic Foundation colorectal laparoscopic conversion (CCF-CLC) scores. Twenty-nine of these patients were converted to open surgery. The demographic and clinical data of the patients were obtained retrospectively. In this study, the conversion score was calculated for each patient by taking into account the CLRROS and CCF-CLC score parameters.

The total score of CLRROS was calculated by evaluating the following parameters: surgical experience, patient history of abdominal surgery, male gender, obesity, tumor diameter, and presence of invasion or metastasis. ${ }^{[2]}$ To obtain the CKLRADS score, the data on ASA class, BMI, surgery type, presence of intraabdominal abscess, and surgical experience were entered into a system dedicated to calculate the rate of conversion to open surgery in percentage (http://www.riskprediction.org.uk/index-ccflap. php).

\section{Statistical Analysis}

All statistical analyses were performed using SPSS version 17.0. The results were obtained as mean \pm standard deviation for non-parametric, continuous variables. Categorical variables were expressed as percentage (\%). Using the receiver operating characteristic (ROC) analysis, the area under the curve (AUC) was scored at 95\% confidence interval (CI). $\mathrm{P}<0.05$ was accepted as statistically significant.

\section{Results}

In this study, among the 126 patients who underwent laparoscopic colorectal resection, the operation was successfully completed in 97 cases (76\%) (classified as Group

Table 1. Demographic and clinical characteristics of the study groups

\begin{tabular}{|c|c|c|}
\hline & $\begin{array}{l}\text { Laparoscopic } \\
\text { resection } \\
\text { Group } 1 \\
(n=97)\end{array}$ & $\begin{array}{c}\text { Conversion to } \\
\text { open surgery } \\
\text { Group } 2 \\
(n=29)\end{array}$ \\
\hline Age (mean $\pm S D)$ & $58 \pm 13$ & $62 \pm 15$ \\
\hline \multicolumn{3}{|l|}{ Gender, n (\%) } \\
\hline Female & $97(100)$ & $15(51)$ \\
\hline Male & $0(0)$ & $14(49)$ \\
\hline CLRROS (mean $\pm S D$ ) & $8 \pm 8$ & $17 \pm 10$ \\
\hline CCF-CLC (mean $\pm S D)$ & $16.6 \pm 9.2$ & $17.7 \pm 10.5$ \\
\hline \multicolumn{3}{|l|}{$\begin{array}{l}\text { Reasons for } \\
\text { conversion, n (\%) }\end{array}$} \\
\hline $\begin{array}{l}\text { Difficulty in } \\
\text { exploration }\end{array}$ & - & $7(24)$ \\
\hline Previous operation & - & $6(20.6)$ \\
\hline Hemorrhage & - & $4(13.7)$ \\
\hline Injury & - & $2(7)$ \\
\hline Invasion & - & $5(17.2)$ \\
\hline Narrow pelvis & - & $1(3.4)$ \\
\hline Liver metastasis & - & $2(7)$ \\
\hline Second tumor & - & $1(3.4)$ \\
\hline Peritoneal disease & - & $1(3.4)$ \\
\hline \multicolumn{3}{|l|}{ Surgical method, n (\%) } \\
\hline LAR & $97(100)$ & $28(96)$ \\
\hline APR & $0(0)$ & $1(4)$ \\
\hline \multicolumn{3}{|l|}{ ASA, n (\%) } \\
\hline II & - & $20(68)$ \\
\hline III & - & $9(32)$ \\
\hline \multicolumn{3}{|l|}{ TNM, n (\%) } \\
\hline T3N1M0 & - & $18(62)$ \\
\hline T4NOMO & - & $7(24)$ \\
\hline T2N2M0 & - & $4(14)$ \\
\hline \multicolumn{3}{|l|}{ BMI, n (\%) } \\
\hline$\geq 28$ & - & $28(96)$ \\
\hline$<28$ & - & $1(4)$ \\
\hline
\end{tabular}

CLRROS: Conversion of laparoscopic rectal resection to open surgery score; CCF-CLC: Cleveland Clinic Foundation colorectal laparoscopic conversion score; LAR: low anterior resection; APR: Abdominoperineal resection; ASA: American Society of Anesthesiology; TNM: Tumor, Node, Metastasis; BMI: Body mass index. 
Table 2. Numeric values for the AUC of CLRROS and CCF-CLC scores according to the ROC analysis

\begin{tabular}{lccc} 
Variable & AUC & $\mathbf{9 5 \%} \mathbf{C l}$ & p-value \\
\hline CLRROS & 0.769 & $0.668-0.871$ & $0.000^{\star}$ \\
CCF-CLC & 0.508 & $0.382-0.634$ & 0.896
\end{tabular}

$\star P<0.05$. CLRROS: Conversion of laparoscopic rectal resection to open surgery score; CCF-CLC: Cleveland Clinic Foundation colorectal laparoscopic conversion score; AUC: Area under the curve; $\mathrm{Cl}$ : Confidence interval.

1), while conversion to open surgery was required in 29 (24\%) (classified as Group 2). The mean age \pm standard deviation (SD) was $58 \pm 13$ and $62 \pm 15$ years for Groups 1 and 2, respectively. In Group 1, all patients (100\%) were female, while in Group 2, 15 (51\%) were female and 14 (49\%) were male. The CLRROS and CCF-CLC scores were $8 \pm 8$ and 16.6 \pm 9.2 , respectively in Group 1, and $17 \pm 10$ and $17.7 \pm 10.5$, respectively in Group 2 (Table 1).

The reasons for the conversion from laparoscopic to open surgery were difficulty of exploration in seven patients (24\%), history of surgery in six $(20.6 \%)$, hemorrhage in four $(13.7 \%)$, injuries in two (7\%), invasion in five (17.2\%), narrow pelvis in one patient (3.4\%), liver metastasis in two patients (7\%), a second tumor in one patient (3.4\%), and a peritoneal disease in one patient (3.4\%).

In Group 2, low anterior resection was performed in 28 patients $(96 \%)$ and abdominoperineal resection in one patient (4\%). In the same group, 20 cases (68\%) were ASA-II

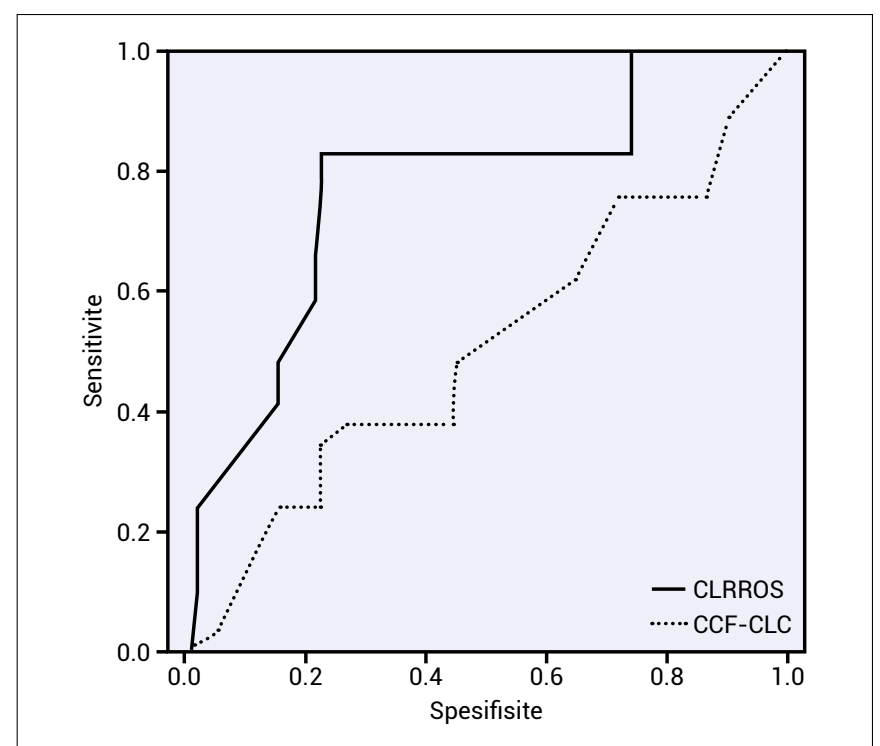

Figure 1. The AUC of CLRROS and CCF-CLC scores according to the ROC analysis. and nine (32\%) were ASA-III. The TNM classification revealed 18 (62\%) T3N1M0, seven (24\%) T4NOMO and four $(14 \%)$ T2N2M0 tumors. The BMI was calculated as $\geq 28$ in 28 patients $(96 \%)$ and $<28$ in one patient $(4 \%)$ in Group 2 (Table 1).

According to the ROC analysis, the AUC values of the CLRROS and CCF-CLC scores were 0.769 (95\% CI: 0.668$0.871, \mathrm{p}=0.000$ ) and 0.508 (95\% CI: 0.382-0.634, $\mathrm{p}=0.896$ ), respectively, indicating that the former had higher power in predicting short-term conversion to open surgery (Table 2 and Fig. 1).

\section{Discussion}

In a randomized controlled trial, conversion from laparoscopic to open surgery in colorectal cancer was reported to be approximately $30 \% \cdot{ }^{[4]}$ Anatomical, patient-related and surgeon-related factors have been suggested as the reasons for such conversion requirement. ${ }^{[5,6]}$ In the current study, the conversion rate was found to be $23 \%$.

A number of models have been developed to predict conversion to open surgery in laparoscopic colorectal procedures. In this context, in the literature, the body surface area has been reported as an independent variable associated with the conversion rate. ${ }^{[7]}$ As examples of different models for the scoring of conversion from laparoscopic to open surgery, Tekkis et al. ${ }^{[8]}$ defined CCF-CLC and GuangDong Zhang et al. ${ }^{[2]}$ presented CLRROS. The AUC for laparoscopic to open surgery conversion was determined as 0.74 (95\% CI 0.68-0.78) in the ROC analysis of the CCF-CLC model ${ }^{[9]}$ and 0.876 for the CLRROS model. ${ }^{[2]}$ In the current study, the AUC values were found to be 0.769 (95\% CI: $0.668-0.871, \mathrm{p}=0.000$ ) and 0.508 (95\% CI: 0.382-0.634, $\mathrm{p}=0.896$ ) for CLRROS and CCF-CLC, respectively. Thus, it was shown that the expected conversion rate significantly differed between the scores obtained from the two models. In addition, in this study, the CLRROS score had higher power in predicting short-term conversion compared to the CCF-CLC score. Similarly, when laparoscopic resection and conversion groups were evaluated, the latter was found to have a significantly higher mean $\pm S D$ value for the CLRROS score compared to CCF-CLC. Concerning the parameters evaluated for the two models, only surgical experience was common. According to the risk factor rate for surgical experience, as surgical experience increased, the rate of conversion to open surgery decreased depending on the learning curve of laparoscopic rectal resection. For the patients included in the study, the resection proce- 
dure was undertaken in a hospital accepted as a reference center in Turkey by surgeons with experience of at least $\geq 50$ laparoscopic surgical operations in the colorectal surgery department.

Studies suggest that BMI, local tumor invasion, and comorbidities are independent risk factors of conversion to open surgery. ${ }^{[4]}$ In the literature, it has been reported that the conversion rate is increased in cases above 65 years, those with a BMI of $\geq 28$, male patients, and in the presence of tumor invasion. ${ }^{[2]}$ Various studies have shown that the need to convert from laparoscopic to open surgery may emerge due to factors, such as advanced age, high ASA class ( $\geq$ III or IV), high BMI, male gender, history of abdominal surgery, local advanced neoplasia, middle and lower rectal cancers, and complicated diverticulitis. ${ }^{[1,4,10,11]}$ In the current study, BMI was $\geq 28$ in most of the patients that required open surgery conversion, with male gender, age and tumor invasion being present at lower rates in this group. Among the reasons for conversion, difficulty of exploration and history of surgery were more frequent. In contrast to the literature, the ASA class was much lower in conversion cases.

Kang et al. ${ }^{[12]}$ suggested that there was no significant difference between open surgery and colorectal resections converted to open surgery in terms of morbidity and mortality. In contrast, Belizon et al., ${ }^{[13]}$ comparing both laparoscopic and open surgery, reported higher rates of complications and longer hospital stay in conversion cases. Although it has been suggested that there is no difference in mortality and morbidity in conversion cases, it is clear that conversion to open surgery increases the cost considering the higher complication rates and longer hospital stay. Preoperative prediction of short-term conversion to open surgery can be useful in turning this adverse situation into an advantage. By providing an accurate estimation of the conversion rate, cases suitable for the laparoscopic approach can be identified, and patients can be better informed about the expected outcomes after surgery.

The main limitation of this study can be considered as its retrospective nature and the small number of cases requiring conversion to open surgery.

In conclusion, male gender, age, tumor invasion and ASA class, which are accepted as risk factors in the literature, were detected at a lower rate among the conversion cases in the current study. Only BMI $\geq 28$ was found to be a significant parameter. This indicates that some parameters are more prominent in models that calculate the risk of short-term conversion. Nevertheless, in the preoperative period, similar scores can be used to predict conversion from laparoscopy to open surgery, and thus to reduce postoperative disadvantages. In addition, it was concluded that these scores can help select cases suitable for the laparoscopic procedure and inform patients about the expected outcomes of surgery.

\section{Disclosures}

Ethichs Committee Approval: The study was approved by the Local Ethics Committee.

Peer-review: Externally peer-reviewed.

Conflict of Interest: None declared.

\section{References}

1. Bhama AR, Obias V, Welch KB, Vandewarker JF, Cleary RK. A comparison of laparoscopic and robotic colorectal surgery outcomes using the American College of Surgeons National Surgical Quality Improvement Program (ACS NSQIP) database. Surg Endosc 2016;30:1576-84. [CrossRef]

2. Zhang GD, Zhi XT, Zhang JL, Bu GB, Ma G, Wang KL. Preoperative prediction of conversion from laparoscopic rectal resection to open surgery: a clinical study of conversion scoring of laparoscopic rectal resection to open surgery. Int J Colorectal Dis 2015;30:1209-16. [CrossRef]

3. Moghadamyeghaneh $Z$, Masoomi $H$, Mills SD, Carmichael JC, Pigazzi A, Nguyen NT, et al. Outcomes of conversion of laparoscopic colorectal surgery to open surgery. JSLS 2014;18. [CrossRef]

4. Allaix ME, Furnée EJ, Mistrangelo M, Arezzo A, Morino M. Conversion of laparoscopic colorectal resection for cancer: What is the impact on short-term outcomes and survival? World J Gastroenterol 2016;22:8304-13. [CrossRef]

5. Li JC, Lee JF, Ng SS, Yiu RY, Hon SS, Leung WW, et al. Conversion in laparoscopic-assisted colectomy for right colon cancer: risk factors and clinical outcomes. Int $\mathrm{J}$ Colorectal Dis 2010;25:983-8. [CrossRef]

6. Ptok $\mathrm{H}$, Kube R, Schmidt U, Köckerling F, Gastinger I, Lippert $\mathrm{H}$; "Colon/Rectum Carcinoma (Primary Tumor)" Study Group. Conversion from laparoscopic to open colonic cancer resection - associated factors and their influence on long-term oncological outcome. Eur J Surg Oncol 2009;35:1273-9. [CrossRef]

7. Vaccaro CA, Vaccarezza H, Rossi GL, Mentz R, Im VM, Quintana GO, et al. Body surface area: a new predictor factor for conversion and prolonged operative time in laparoscopic colorectal surgery. Dis Colon Rectum 2012;55:1153-9. [CrossRef]

8. Tekkis PP, Senagore AJ, Delaney CP. Conversion rates in laparoscopic colorectal surgery: a predictive model with, 1253 patients. Surg Endosc 2005;19:47-54. [CrossRef]

9. Vaccaro CA, Rossi GL, Quintana GO, Soriano ER, Vaccarezza 
$H$, Rubinstein F. Laparoscopic colorectal resections: a simple predictor model and a stratification risk for conversion to open surgery. Dis Colon Rectum 2014;57:869-74. [CrossRef]

10. Biondi A, Grosso G, Mistretta A, Marventano S, Tropea A, Gruttadauria S, et al. Predictors of conversion in laparoscopic-assisted colectomy for colorectal cancer and clinical outcomes. Surg Laparosc Endosc Percutan Tech 2014;24:e216. [CrossRef]

11. Bhama AR, Charlton ME, Schmitt MB, Cromwell JW, Byrn JC. Factors associated with conversion from laparoscopic to open colectomy using the National Surgical Quality Improvement Program (NSQIP) database. Colorectal Dis 2015;17:257-64. [CrossRef]

12. Kang CY, Chaudhry OO, Halabi WJ, Nguyen V, Carmichael JC, Stamos MJ, et al. Outcomes of laparoscopic colorectal surgery: data from the Nationwide Inpatient Sample 2009. Am J Surg 2012;204:952-7. [CrossRef]

13. Belizon A, Sardinha CT, Sher ME. Converted laparoscopic colectomy: what are the consequences? Surg Endosc 2006;20:947-51. [CrossRef] 